\title{
EDUCACIÓN, ARTE Y CULTURA POLÍTICA EN LA POSMODERNIDAD
}

\author{
Hamlet Fernández Días (Universidad de La Habana)*
}

\section{RESUMEN}

En el artículo se realiza una sistematización de la propuesta de Fredric Jameson de "estética del trazado de mapas cognitivos", pensada desde el arte y con fines pedagógicos. Se plantea el objetivo de profundizar en la reflexión teórica sobre las posibilidades desarrolladoras de una arte-educación basada en la estética de mapas cognitivos, un tipo de pedagogía a través del arte que contribuya a la formación de cultura política en la condición histórica de la posmodernidad. Se concluye, a través de un ejemplo, que el arte contemporáneo, al producir mapas estéticos y conceptuales de diversas problemáticas de actualidad, y por el tipo de comunicación/comprensión que exige del receptor, puede ser un revelador punto de partida para la formación de un sujeto capaz de reescrituras críticas del propio devenir existencial, lo cual implica una concientización del lugar que se ocupa en la realidad social.

Palabras clave: Arte y educación. Mapa cognitivo. Posmodernidad. Cultura política. Interdisciplinariedad.

\section{RESUMO}

\section{EDUCAÇÃO, ARTE E CULTURA POLÍTICA NA PÓS-MODERNIDADE}

0 artigo sistematiza a proposta de Fredric Jameson de uma "estética do desenho de mapeamento cognitivo", concebida a partir da arte e com fins pedagógicos. Propõe como objetivo, aprofundar a reflexão teórica sobre as possibilidades de desenvolvimento de uma arte-educação com base na estética do mapeamento cognitivo, um tipo de educação através da arte que contribui para a formação de cultura política na condição histórica da pós-modernidade. Conclui-se, através de um exemplo, que a arte contemporânea, ao produzir mapas estéticos e conceituais de várias problemáticas da atualidade, e pelo tipo de comunicação/ compreensão que exige do receptor, pode ser um ponto de partida revelador para a formação de um sujeito capaz de reescritas críticas do próprio desenvolvimento existencial, o que implica uma tomada de consciência do lugar que se ocupa na realidade social.

Palavras chave: Arte e educação. Mapa cognitivo. Pós-modernidade. Cultura política. Interdisciplinaridade.

* Doctor en Ciencias sobre Arte por La Universidad de La Habana, Cuba. Bolsista de Posdoctorado en la Universidad de Uberaba (Uniube). E-mail: hamletfdez84@gmail.com 


\section{ABSTRACT}

\section{EDUCATION, ART AND POLITICAL CULTURE IN POSTMODERNITY}

In the article, a systematization of Fredric Jameson's proposal of "aesthetics of cognitive mapping" is made, thought from the art and with pedagogical purposes. The objective is to deepen the theoretical reflection on the development possibilities of an art-education based on the aesthetics of cognitive maps, a type of pedagogy through art that contributes to the formation of political culture in the historical condition of postmodernity. It is concluded, through an example, that contemporary art, by producing aesthetic and conceptual maps of various current issues, and by the type of communication / understanding that requires of the receiver, can be a revealing starting point for the formation of a subject capable of critical rewriting of the own existential becoming, which implies an awareness of the place occupied in the social reality.

Keywords: Art and education. Cognitive map. Postmodernity. Political culture. Interdisciplinarity.

\section{Introducción ${ }^{1}$}

Fredric Jameson (Cleveland, Ohio, 1934) es uno de los teóricos marxistas ocupado con temas del arte y la cultura de mayor renombre internacional. Desde su Marxism and Form (JAMESON, 1971) publicado en 1971, hasta su más reciente Raymond Chandler: The Detections of Totality (JAMESON, 2016), Jameson ha publicado más de 25 obras escritas originalmente en inglés, a lo que se debe sumar las traducciones de muchas de esos libros a varios idiomas, ediciones de compilaciones de ensayos, etc.; lo que ha posibilitado una extraordinaria promoción internacional de su trabajo teórico y crítico. Esa consistente producción teórica cubre temas, fenómenos y problemáticas filosóficas, epistemológicas, estéticas, políticas y culturales en su sentido amplio, que han ocupado muchas veces el centro de los debates intelectuales a nivel internacional desde la década del sesenta del siglo XX hasta la actualidad.

Uno de esos temas ha sido, como se sabe, la posmodernidad. Desde mediados de la década del ochenta del pasado siglo Fredric Jameson se convirtió en una de las voces fundamentales

1 Apoyo a la investigación: PNPD/CAPES; FAPEMIG. del debate filosófico sobre la posmodernidad. Su ensayo Postmodernism: the Cultural Logic of Late Capitalism (JAMESON, 1984), publicado en la New Left Review en 1984, tuvo una repercusión inmediata en los circuitos intelectuales de habla inglesa; y su traducción al castellano por Esther Pérez para la revista Casa de las Américas (JAMESON, 1986) lo convirtió rápidamente en un texto de referencia para la crítica cultural de izquierda en América Latina. A este ensayo Jameson sumaría otros en los que amplía y profundiza su enfoque y tesis fundamentales sobre la posmodernidad (JAMESON, 1991, 2002).

En El posmodernismo como lógica cultural del capitalismo tardío (JAMESON, 1991), a contracorriente de las fuertes tendencias del momento que proclamaban un pensamiento anti-totalitario, anti-esencialista, de micro-resistencias, de puesta en crisis de los grandes metarrelatos históricos, lineales y teleológicos, etc., el autor no se contuvo de pensar históricamente e introdujo una propuesta de hipótesis de periodización basada en la dialéctica marxista, a saber: el posmodernismo como dominante cultural. Y advirtió que esa dominante cultural no podía ser entendida superfi- 
cialmente en términos de estilos estéticos, de simples modas o tendencias artísticas, o como un sistema cultural autónomo, desconectado de los modos de producción de un capitalismo que se hallaba en su tercera fase de evolución, ahora sí, en una escala totalmente global y no parcial, como en sus fases precedentes.

Desde ese ensayo inicial la posmodernidad fue para Jameson una cuestión estructural; la posmodernidad sería en sí la sociedad capitalista internacional o multinacional, y el posmodernismo su dominante cultural: la expresión superestructural del Capital en una tercera o cuarta fase de desarrollo posibilitada por la última gran revolución tecnológica (la cibernética, la informática, la energía atómica, los sistemas de conectividad global, la inteligencia artificial, etc.). Mantener la hipótesis marxista de que los procesos culturales deben ser siempre puestos en relación, o más bien pensados dialécticamente en los marcos de desarrollo de un modo de producción o estructura social, ha sido fundamental para Jameson, porque de lo contrario nos advierte que se puede retroceder con gran facilidad a un tipo tradicional de "historia intelectual", de las culturas o de las civilizaciones, en la que "las cosas suceden sin ninguna lógica en particular" (JAMESON, 1992, p. 45).

Para hacer emerger a la conciencia teórica el mapa cognitivo del posmodernismo como lógica cultural del capitalismo tardío, el catedrático de Duke University propuso la conceptualización de una serie de "síntomas estéticos" constitutivos de dicha lógica dominante; un enfoque que toma prestado de Raymond Williams y que contempla a la vez, integrando un mismo campo de fuerzas contrapuestas, formas "residuales" y "emergentes" de producción cultural. Lo extraordinario de su movimiento metodológico es la manera en que invierte la lógica del marxismo clásico que tiende a explicar la superestructura a partir de un análisis de la estructura social, pues la primera, en última instancia, se considera que estará determinada por la segunda. No es que Jameson renuncie a esta hipótesis de base, por el contrario, pero sí invierte la metodología de análisis: su bosquejo del posmodernismo parte del análisis interpretativo, del desmontaje estructural de las formas más sutiles y complejas de expresión cultural como son las obras de arte, para encontrar así su determinación más profunda en la historia, eso es, en el tipo de relaciones sociales y de producción que siguen constituyendo las "reales condiciones de existencia" en la sociedad contemporánea.

El otro elemento a resaltar es que la producción de nuevas categorías de análisis, más ajustadas a los fenómenos culturales actuales, son generadas en el propio proceso interpretativo de obras y tendencias concretas, en el que Jameson suele echar mano de diversas disciplinas y enfoques teóricos. Por tanto, su manera de producir conocimiento es profundamente interdisciplinar. Cada hipótesis interpretativa genera un nuevo nivel de reflexión en el que se van articulando herramientas conceptuales aportadas por diferentes disciplinas (marxismo, hermenéutica, estética filosófica, psicoanálisis, semiótica, cartografía, etc.), en función del objetivo mayor de arribar a una comprensión cada vez más integral y dialéctica del fenómeno de que se trate. Y el arte ocupa un lugar central en esa conceptualización porque es punto de partida, es el dispositivo cultural complejo que permite y exige una plataforma interdisciplinar de reflexión.

Los "síntomas estéticos" conceptualizados por Jameson han llegado a ser célebres: una nueva cultura de las superficies, la imagen, el simulacro, de la pérdida de la profundidad o la densidad cultural; la dominancia de un procedimiento estético-discursivo como el "pastiche", por sobre un procedimiento más antiguo como la paródica; la pérdida de la historicidad, de la mano de la estetización espectacular y acrítica del pasado; formas de temporalidad y de textualidad esquizofrénicas; una nueva concepción y experiencia del espacio; nuevos fenómenos objeto de lo sublime filosófico, lo sublime histérico o posmoderno; así como la 
necesidad de construir estéticas de mapas cognitivos desde el arte, un nuevo arte político que pueda jugar también un importante y decisivo rol pedagógico (JAMESON, 1991).

Todas estas características constitutivas del posmodernismo formuladas por Fredric Jameson han sido ampliamente comentadas, discutidas, subrayadas, criticadas y utilizadas, durante los 34 años de vida que ya tiene su memorable ensayo. Sin embargo, llama la atención que su tesis final, acerca de la necesidad de poner en primer plano las dimensiones cognitivas y pedagógicas del arte, para dotar al sujeto de herramientas que le permitan articular su experiencia empírica con una comprensión teórica de la totalidad social, nacional y global, ha sido poco trabajada en función de la educación a través del arte. ${ }^{2}$ Ese es precisamente el objetivo que nos trazamos en este trabajo: desarrollar la propuesta de Fredric Jameson de una "estética del trazado de mapas cognitivos", en función de un tipo de pedagogía a través del arte que dé cuenta de los retos que afronta la educación en la formación de una cultura política, crítica, en la condición histórica de la posmodernidad.

En lo que sigue, sistematizaremos con la mayor brevedad las bases conceptuales de las que parte Jameson para formular su modelo que imbrica arte, función pedagógica y cultura política, pensado de manera interdisciplinar para responder a las necesidades cognoscitivas del sujeto; ese "sujeto posmoderno" inmerso en un nuevo tipo de espacio social internacional y "aturdidor", generado por el "capital multinacional tardío" (JAMESON, 1991, p. 22). Sobre esa base, reflexionaremos sobre las posibilidades formativas de una enseñanza basada en el trazado de mapas cognitivos en la dimensión simbólica y estética que genera el arte.

2 En Cuba, por ejemplo, las tesis y categorías de Jameson sobre la posmodernidad son objeto de estudio en la academia, y han influenciado ampliamente el campo de la reflexión teórico-estética, la crítica de arte, la creación artística; pero en el ámbito de la enseñanza de arte no hemos encontrado ninguna aplicación de sus ideas sobre la dimensión pedagógicas de la estética de mapas cognitivos.

\section{Fundamentos de una estética del trazado de mapas cognitivos}

El concepto de "mapa cognitivo" ha sido desarrollado por algunas disciplinas como la geografía, la cartografía, el urbanismo, la psicología ambiental. La literatura especializada refiere que su origen se remonta a comienzos del siglo XX, cuando en 1913 el geógrafo Trowbridge desarrolló la noción de "mapas imaginarios" para estudiar la representación mental de los ambientes físicos. Posteriormente, en 1948 un psicólogo conductista, Edward C. Tolman, publicó una obra titulada Cognitive Maps in Rats and Men, en la que estudiaba la función que las imágenes mentales jugaban, tanto en ratas como en humanos, en la orientación de recorridos (RICART, 2009).

La definición más general que se puede dar de mapas cognitivos es la de ser una "expresión mental que el cerebro elabora del medio que le rodea". Para la psicología ambiental se trata de un "dispositivo mental que codifica y simplifica la forma en que nuestro entorno se organiza" (RICART, 2009, p. 4). Los procesos de codificación y simplificación son muy importantes. La configuración de un mapa cognitivo en la dimensión mental implica la codificación de esa relación espacial que establece el individuo con el medio ambiente, pero dicha codificación distorsiona hasta cierto punto la información que se obtiene del entorno; a la vez, se produce una síntesis, imprescindible, de ese cúmulo de información en diferentes niveles: "la topológica, la métrica, los recorridos, las referencias fijas y las imágenes sensoriales" (RICART, 2009, p. 7).

El referente concreto del que parte Jameson es el libro The Image of the City, de 1960, del urbanista norteamericano Kevin Lynch (1990). Esta obra, considerada un clásico del diseño urbano, se inscribe en una tendencia que comenzó a desarrollarse a comienzos de la década del sesenta del siglo XX, la cual valoriza la experiencia del espacio que tiene el usuario. Lynch estudió tres ciudades de los 
Estados Unido (Boston, New Jersey y Los Ángeles) aplicando un método de trabajo de campo que le permitiera obtener las percepciones, las valoraciones, las "imágenes ambientales" que tenían formadas los ciudadanos de los espacios urbanos y la ciudad en la que habitaban. Su objetivo final era dar respuesta a problemas de diseño ambiental y su adecuación al usuario, con base en su propia experiencia.

A Fredric Jameson, más que la problemática propiamente urbanística o de representación cartográfica, lo que le interesa explotar es la metáfora del mapa cognitivo de cara a problemáticas espaciales, sociales, culturales y políticas que atraviesan la experiencia empírica del sujeto en una dimensión más abstracta que la de la relación inmediata con el entorno en el que se vive.

Kevin Lynch nos reveló que la ciudad alienada es sobre todo un espacio en el que las personas son incapaces de representarse (mentalmente) su propia posición o la totalidad urbana en la que se encuentran [...] Por tanto, la desalienación en la ciudad tradicional supone la real reconquista de un sentido de lugar, y la construcción o reconstrucción de un conjunto interrelacionado que pueda ser retenido en la memoria, y que el sujeto individual pueda trazar y volver a trazar en un mapa en los momentos de trayectorias alternativas. (JAMESON, 1991, p. 82).

Si esta interpretación es correcta, si sucede así con relación a la representación mental del espacio concreto en el que se habita (algo que podemos comprobar basados en la experiencia personal), pudieran extrapolarse entonces estos principios a un nivel más general y abstracto, para plantear una hipótesis preliminar: una cultura política alienada, tanto a nivel individual como colectivo, sería aquella en la que el sujeto se muestra incapaz de generar representaciones mentales (mapas cognitivos) de su propia posición de clase, género, raza, cultura, etc., en la totalidad social en la que existe. Por consiguiente, la desalienación cultural del sujeto, si es que esto es posible, debiera implicar una conquista cognoscitiva de ese sentido o conciencia del lugar que se ocupa en el mundo, así como de una memoria funcional de las trayectorias existenciales que nos conectan en diversas dimensiones con la totalidad difusa.

Jameson reconoció en escritos posteriores que con la noción de "mapa cognitivo" se refería en realidad, aunque de forma algo encubierta, cifrada, a la problemática de la "conciencia de clase" (JAMESON, 2002, p. 73). En una entrevista publicada en la revista El Cielo por Asalto, también argumentaría de forma explícita:

En referencia al punto de las clases sociales y los mapas cognitivos, es que es obvio que estamos en una situación donde el mundo es tan complicado, y las redes del poder social tan minuciosas, que resulta muy difícil para la gente orientarse como sujetos de clase dentro de esta totalidad. No creo ni por un instante que las clases en sí [as such] han desaparecido [...] Pero, las formas de conciencia de clase que corresponderían a la nueva división global del trabajo, y la nueva situación global, todavía no han aparecido, porque esto es demasiado nuevo. Por ello, lo que el mapa cognitivo intenta hacer como una forma de la conciencia de clase es doble, y por esto es que es igualmente epistemológica, y cultural y utópica a la vez.

Epistemológicamente, me parece que se tiene que insistir, en primer lugar, en todas las dificultades que tenemos en ver nuestra posición de clase en esta enorme realidad global, y se tienen que perseguir las dificultades de estas cosas para todos los otros sujetos sociales alrededor nuestro. [...] Esa conciencia de clase sería entonces, me parece, el elemento utópico en estos otros mapas del mundo. (JAMESON, 1992, p. 54-55).

La dimensión cultural de la propuesta tiene que ver, por su puesto, con el arte, con la potencialidad política y formativa que le es intrínseca; por lo que Jameson considera que "no es imposible imaginar maneras en que un arte posmoderno enseñaría a la gente acerca de la estructura del mundo" (JAMESON, 1991, p. 55). De hecho, existen innumerables artistas cuyo trabajo podría ser citado como ejemplo de lo anterior. De ahí que en El posmodernismo como lógica cultural del capitalismo tardío (JAMESON, 1991) el autor termine ubicando la metáfora del trazado de estéticas de mapas 
cognitivos en el plano de lo simbólico, y no en el de la ideología.

Jameson expone un argumento convincente para justificar ese corrimiento estratégico desde un concepto con peso dentro de la tradición marxista, como el de ideología, hacia otro que entra de lleno en el terreno del psicoanálisis, como el de lo "simbólico lacaniano". Su primer movimiento metodológico va de la metáfora cartográfica al concepto de ideología de Louis Althusser, porque este le permite extrapolar la cuestión de la representación mental del espacio hacia el terreno de las relaciones sociales y su representación imaginaria. El concepto de ideología de Althusser tiene sus paralelos con la noción de mapa cognitivo. En sus términos ideología deja de ser "falsa conciencia", imagen invertida o engañosa de la realidad, creada por la clase dominante para que las clases oprimidas no puedan acceder a la verdad de su condición de explotados. La ideología, dice Althusser, es la representación imaginaria que nos hacemos de nuestra relación con las "reales condiciones de existencia". Por tanto, se podría decir que para Althusser la ideología es algo así como nuestro mapa cognitivo, es lo que nos permite orientarnos en la realidad, es la base de nuestro punto de vista empírico, monádico, existencial. No existe sujeto fuera de la ideología, decir sujeto ideológico es una tautología, según el autor. Todos, absolutamente todos, desde los hombres más poderosos hasta los más desposeídos, estamos inmersos en una representación imaginaria, ideológica, a través de la cual establecemos contacto con la realidad concreta (ALTHUSSER, 2003).

El otro punto a destacar es que Althusser mantiene la distinción hecha por Marx entre ciencia e ideología: solo la ciencia permite acceder a un conocimiento "verdadero" de las leyes profundas de la historia que determinan nuestra existencia; por su parte, la ideología ocupa el plano imaginario -aunque con expresiones materiales concretas-, reducido al punto de vista del sujeto. La diferencia está en que para el filósofo francés el científico es también, desde siempre, un sujeto ideológico (valga la redundancia); mas solo un método científico de análisis de la realidad permite establecer una distancia crítica con respecto a la condición irreductible de estar sujeto a una ideología. Es decir, solo la ciencia nos permite tomar conciencia crítica de la ubicuidad de la ideología. También hay que señalar que Althusser estableció una diferencia esencial entre arte e ideología. El arte, con su especificidad, también nos permite vivir críticamente la manera en que se expresa la ideología (ALTHUSSER, 1967).

El punto en el que Jameson se distancia del modelo dualista de Althusser (ideología/imaginario versus ciencia/realidad), se focaliza sobre sus tesis de que la ideología juega el decisivo rol de tender un puente por sobre la brecha que se abre entre la experiencia empírica que tiene el sujeto de su relación con la realidad, y el conocimiento científico, que es el único que en principio puede decir algo "verdadero" sobre la realidad. En el modelo del Althusser, la clase dominante (o las alianzas de clase) que ostenta el poder de Estado, controla los "aparatos represivos" y los "aparatos ideológicos"; y fundamentalmente a través de los segundos imponen al resto de la sociedad su ideología, es decir, su visión de mundo, sus "verdades", sus valores, sus principios, sus costumbres, sus prácticas culturales concretas y materiales. Esa ideología dominante juega un rol de cohesión social, es la base sobre la que se sostiene la legitimación del poder de Estado para ejercer su hegemonía. Por tanto, la reproducción de la ideología dominante es consustancial a la reproducción del Poder; y como en la sociedad capitalista se trata del poder hegemónico de la burguesía, advierte Althusser que la reproducción de la ideología dominante es la que asegura, en última instancia, la reproducción de la fuerza de trabajo que mueve los medios de producción del Capital. A ello contribuyen todos los Aparatos Ideológicos de Estado (AIE), en especial el binomio escuela-familia. Porque, para el autor, en el proceso de estructuración de 
la sociedad moderna capitalista la institución escolar se convierte en el principal AIE, como lo fue antes la Iglesia en la sociedad premoderna. ${ }^{3}$

La objeción de Jameson a este aspecto de la concepción althusseriana se basa en el razonamiento siguiente:

[...] la fórmula de Althusser apunta a una brecha, una grieta entre la experiencia existencial y el conocimiento científico: de aquí que la ideología asuma la función de inventar alguna forma de articular entre sí esas dos dimensiones distintas. Lo que querría agregar a esta 'definición' un punto de vista historicista es que tal coordinación, la producción de ideologías vivas y actuantes, es diferente en las distintas situaciones históricas, pero, sobre todo, que puede haber situaciones históricas en las que ello resulte absolutamente imposible: esta parecería ser nuestra situación en la crisis actual. (JAMESON, 1991, p. 86-86).

La situación actual es muy diferente a la del siglo XIX o incluso a la de la primera mitad del siglo XX, cuando la burguesía como clase hegemónica en el Poder podía reproducir con cierta uniformidad su ideología en la Escuela, la Iglesia, los Medios de Comunicación tradicionales, el Arte Académico, etc. Fue precisamente el modernismo estético y después con mayor radicalidad las vanguardias históricas, quienes en su afán de subversión del academicismo terminaron erosionando de manera radical los valores y rituales de la cultura burguesa. Otro de los procesos históricos que llevó a cabo un profundo desgaste de los valores cohesionadores del capitalismo decimonónico

3 “[...] ¿cómo se asegura esta reproducción de la calificación (diversificada) de la fuerza de trabajo en el régimen capitalista? Contrariamente a lo que sucedía en las formaciones sociales esclavistas y serviles, esta reproducción de la calificación de la fuerza de trabajo tiende (se trata de una ley tendencial) a asegurarse no ya 'en el lugar de trabajo' (aprendizaje en la producción misma), sino, cada vez más, fuera de la producción, por medio del sistema educativo capitalista y de otras instancias e instituciones. [...] Enunciando este hecho en un lenguaje más científico, diremos que la reproducción de la fuerza de trabajo no sólo exige una reproducción de su calificación sino, al mismo tiempo, la reproducción de su sumisión a las reglas del orden establecido, es decir una reproducción de su sumisión a la ideología dominante por parte de los agentes de la explotación y la represión, a fin de que aseguren también "por la palabra" el predominio de la clase dominante" (ALTHUSSER, 2003, p. 13-14). norteamericano, a saber, el "temperamento puritano" y la "ética protestante", fue la propia constitución de la "sociedad de consumo" a lo largo del siglo XX, con su glorificación de la cultura del ocio, el hedonismo, la liberación sexual, la estetización de la vida cotidiana etc. (BELL, 1989). Esta tesis, avanzada por Daniel Bell en su libro Las contradicciones culturales del capitalismo, concluye con un diagnóstico histórico muy semejante al de Jameson: la sociedad postindustrial (para Bell), y el capitalismo en su escala global, multinacional (para Jameson), ha dejado de tener una ideología hegemónica que lo legitime como sistema.

¿Qué hacer entonces cuando se verifica un fenómeno de esta naturaleza? Para Daniel Bell, sociólogo tildado de neoconservador, la única solución posible se hallaba en un resurgimiento religioso con la suficiente fuerza como para suplir la profunda crisis de legitimación que padece el sistema; de lo contrario, la sociedad a la deriva, sin un sistema de valores que de cohesión a la estructura social, se encamina hacia el caos.

La solución utópica que sugiere Jameson es muy diferente. Aquí es donde se aproxima a Lacan, porque su compleja concepción del sujeto se basa en un sistema compuesto por tres planos estrechamente interrelacionados: lo Imaginario, lo Simbólico y lo Real. En ese momento, y un tanto obviando el principio de Lacan de que el sujeto es siempre un nudo que entrelaza las tres dimensiones, Jameson jerarquiza el plano de lo simbólico, por ser la variable omitida tanto en el sistema de Marx como en el de Althusser. Su conclusión final en el ensayo que nos ocupa fue por tanto que una estética del trazado de mapas cognitivos debería operar en el plano de lo simbólico; entendiendo más el término en el sentido de la representación estética. ${ }^{4}$

4 "Una estética del trazado de mapas cognitivos -una cultura política pedagógica que trate de proporcionarle al sujeto individual un nuevo y más elevado sentido del lugar que ocupa en el sistema global- tendrá necesariamente que respetar esta dialéctica de la representación que es ya enormemente compleja, y tendrá también que intentar formas radicalmente nuevas a fin de hacerle justicia. [...] 
Ahora bien, como nuestro interés principal es enrumbar la reflexión hacia el objetivo de pensar la posibilidad de una propuesta pedagógica a través del arte basada en la estética de mapas cognitivos, conviene detenernos un poco más en el sistema de Lacan, porque sus implicaciones para una teoría del sujeto son de vital importancia para la educación.

Como se sabe, las nociones lacanianas de lo Imaginario y lo Real nada tienen que ver con las representaciones mentales consideradas imaginarias (en el sentido tradicional que tiene la categoría de imaginación) o con la realidad concreta inmediata. A su vez, el plano de lo Simbólico, entendido como lo históricamente determinado, el lenguaje codificado, el ordenamiento cultural en su sentido más general, no puede entenderse disociado de los otros dos planos en lo que a la dimensión del sujeto se refiere. A lo largo de su vida y de sus 27 Seminarios, Lacan fue reformulando continuamente la definición de estas categorías como si fuera imposible decir la última palabra sobre ellas. Por otro lado, la interpretación que hacen los muchos comentadores de su obra también varía considerablemente una de otra. Sin poder detenernos aquí en las muchas sutilezas teóricas de esta discusión, vamos a intentar resumir una comprensión de los tres planos y la manera en que se articulan, partiendo directamente de Lacan.

Lo Imaginario es lo incognoscible en sí mismo, es una línea de ficción que comienza a configurarse a partir del "estadio del espejo" (LACAN, 2003a). Está estructurado por formas de lenguajes, por tanto, posee una determina-

el nuevo arte político -si es que este arte resulta posibletendrá que asimilar la verdad del posmodernismo, esto es, de su objeto fundamental -el espacio mundial del capital multinacional- al tiempo que logre abrir una brecha hacia un nuevo modo aún inimaginable de representarlo, mediante el cual podremos nuevamente comenzar a aprehender nuestra ubicación como sujetos individuales y colectivos y a recobrar la capacidad para actuar y luchar que se encuentra neutralizada en la actualidad por nuestra confusión espacial y social. La forma política del posmodernismo, si es que va a existir, tendrá como vocación la invención y proyección del trazado de un mapa cognitivo global, a escalas social y espacial" (JAMESON, 1991, p. 86). ción social; pero se trata de significantes puros, eso es, un lenguaje particular carente de codificación, aunque con expresiones materiales concretas (imágenes, sueños, fobias, paranoias, perversiones fetichistas, etc.). Con respecto a lo Simbólico, Lacan concuerda con las tendencias teóricas más influyentes de su época (lingüística y antropología estructural, iconología, semiótica, filosofía del lenguaje, etc.) en que el símbolo es "el registro esencial a la realidad humana", y que el lenguaje, en tanto convención social, es la actividad simbólica por excelencia. Es así que "lo imaginario sólo es descifrable si es traducido en símbolos" (LACAN; GRANOFF, 2018). Ese es el objetivo de la cura hablada del psicoanálisis, propiciar un trasvase hacia el plano codificado del lenguaje para así poder descifrar la línea de ficción a-simbólica que se proyecta desde el plano de lo Imaginario. ${ }^{5}$

Ahora bien, más allá del campo específico de las patologías psíquicas, esta interrelación entre los planos Imaginario y Simbólico sigue siendo una hipótesis de validez general: acontece en todos los sujetos, porque es constitutiva de la estructura psíquica. Solo que cuando no se verifican síntomas patológicos, es porque se supone que el "trabajo de lo simbólico" mantiene el control sobre los significantes puros del imaginario personal; siendo el fenómeno inverso el que genera trastornos mentales. En el complejo proceso de desarrollo de la psiquis, es el tránsito azaroso desde la fase inicial de lo Imaginario (que no está exento de determinación social) hacia la estructuración de lo Simbólico, el que marca la entrada de la "cría de hombre" al reino de la cultura, esto es, la realidad propiamente humana. A partir de ese umbral, la línea de ficción del imaginario acompañará el devenir del sujeto, pero mediatizada, reestructurada incesantemente dentro del Orden de lo Simbólico, en ese intento angustioso

\footnotetext{
5 "El elemento imaginario sólo tiene valor simbólico, el cual deber ser evaluado y comprendido a la luz del momento particular del análisis en el que acaece. Esta fantasía se crea para expresarse a sí misma, para ser dicha, para simbolizar algo que puede tener un significado completamente diferente en el momento del diálogo" (LACAN; GRANOFF, 2018, p. 5).
} 
de todo sujeto por enmarcar su experiencia existencial dentro de las leyes que estructuran la vida en sociedad.

Esta problemática es vital para la educación. En su función más general la escuela, después del ámbito familiar, es el lugar de reproducción por excelencia del Orden de lo Simbólico. Desarrollar y robustecer el plano de lo simbólico, para formar sujetos funcionales, capaces de desempeñar un rol en la sociedad, es objetivo fundamental de toda educación. Ahora, ese objetivo se puede desenvolver al menos por dos caminos muy diferentes. El tradicional, que es el de la pedagogía de la domesticación, cuando la escuela se comporta como una institución garante de reproducción de la ideología dominante (como bien advierte Althusser); o el camino que robustece las competencias del plano de lo Simbólico para formar sujetos conscientes de que ese Orden de lo Simbólico es una realidad construida por el hombre, y por ende susceptible de ser interpretada, cuestionada, reformada o radicalmente transformada.

Es hora entonces de traer a colación el tercero de los planos de Lacan, el de lo Real. Cuando en la discusión final de uno de los Seminarios Serge Leclaire le pregunta al maestro: "Usted nos habló de lo simbólico, de lo imaginario, pero estaba lo real, de lo que no habló", Lacan le contesta: "Sin embargo, un poco hablé. Lo real es la totalidad o el instante que se desvanece" (LACAN, 2005, p. 54). Fredric Jameson, en su libro Imaginario y Simbólico en Lacan, rescata esta otra frase suya: "lo Real, o lo que es percibido como tal, es lo que resiste a la simbolización en forma absoluta" (LACAN apud JAMESON, 1995, p. 48). Acto seguido Jameson (1995, p. 48-49) concluye:

Sin embargo, no es demasiado difícil decir cuál es el significado de lo Real en Lacan. Es simplemente la Historia misma; y si para el psicoanálisis la historia en cuestión aquí, como es suficientemente obvio, es la historia del sujeto, la resonancia de la palabra sugiere que no puede postergarse por más tiempo un enfrentamiento entre este materialismo particular y el materialismo histórico de Marx. Es un enfrentamiento cuyo primer ejemplo ha sido establecido por el mismo Lacan, con su proposición de que la noción de lo Simbólico, como él la usa, es compatible con el marxismo (cuya teoría del lenguaje, como muchos marxistas estarían dispuestos a coincidir, permanece sin formulación).

Jameson considera, al igual que Althusser, que uno de los grandes méritos de Lacan es el de haber logrado explicitar la teoría lingüística que estaba implícita en el sistema teórico de Freud (LACAN, 2003b). A través de la lingüística estructural Lacan hace posible la objetivación del inconsciente; aquel "objeto" puramente teórico deja de ser mera abstracción en la medida en que sus efectos adquieren una materialidad que la teoría del lenguaje permite percibir y analizar (entrada del imaginario en la dinámica de simbolización mediante la cura hablada). Por eso Jameson se arriesga a decir que el psicoanálisis, al igual que el marxismo, es un materialismo, solo que cada uno revela un área diferente en la que la conciencia humana no es "amo en su propia casa": para el psicoanálisis se trata de la historia personal del sujeto anclada en su sexualidad; para el marxismo, la dinámica de clases de la historia social (JAMESON, 1995, p. 50).

Una última precisión de Jameson nos llama la atención sobre el hecho de que la Historia no es exactamente un texto, como pretenden determinadas filosofías del lenguaje. La Historia con mayúsculas, equivalente a lo Real lacaniano, es siempre una "causa ausente", que es debido reconstruir, eso sí, como un texto, para de esa forma poder llenar el vacío y acercarse a su conocimiento y comprensión. La Historia, o lo Real, es la "totalidad" siempre ausente, el "instante que se desvanece", aquello que estamos obligados a textualizar, a convertir en narrativa, para así hacerlo entrar en el plano de lo Simbólico. Es en esa dimensión que se ubica la estética de mapas cognitivos a ser trabajada desde el arte. Extraer cartografías cognitivas desde el arte es propiciar una actividad simbolizadora consciente, tanto de la historia personal como colectiva. Por eso Jameson se sitúa en un punto de convergencia entre marxismo y psicoanálisis, 
porque ambas praxis construyen narrativas, el primero del devenir social colectivo, el segundo del devenir individual del sujeto. Dichas narrativas deben ser pensadas como reconstrucciones constantes, interminables, porque cada esfuerzo será limitado y contingentemente histórico. Pero nunca debemos confundir, advierte Jameson, la narrativa de la historia que se construye con lo Real mismo, porque lo Real, en tanto totalidad, es lo que "resiste absolutamente la simbolización".

\section{Reflexión sobre una educación a través del arte basada en la estética de mapas cognitivos}

El arte es uno de los esfuerzos humanos de simbolización que más contribuye, desde lo individual, a esa gesta colectiva de intentar acercarse a lo Real mismo mediante la textualización de fragmentos de la totalidad siempre ausente, ya sea de historias particulares, personales o colectivas. La propuesta de Fredric Jameson de una estética del trazado de mapas cognitivos se inscribe en el horizonte siempre utópico de una educación progresista, contraria a la "domesticación" o el "atontamiento", precisamente porque propone extraer del arte cartografías simbólicas que contribuyan a hacer emerger las nuevas formas de conciencia de clase que se corresponden históricamente con la "enorme realidad global contemporánea". Ese sería el aspecto utópico, la emergencia de nuevas formas de conciencia de clase. Corresponde entonces a la dimensión epistemológica trabajar en pos de la contribución a una cultura política acorde a la complejidad de la sociedad actual.

Una arte-educación basada en la estética de mapas cognitivos debe asumir ese reto epistemológico, instrumentando metodológicamente las posibilidades que brinda el arte contemporáneo para el trazado de mapas cognitivos; lo cual significa, en última instancia, robustecer el plano Simbólico del sujeto en el sentido de desarrollar habilidades que le permitan situarse de manera activa y con conciencia, dentro del juego infinito de las narraciones de la Historia, propia y colectiva. Entre otras tantas razones, la experiencia que nos provoca el arte puede convertirse en un hecho liberador o emancipatorio en la medida en que el diálogo con las obras nos motive a una reescritura crítica, en primer lugar, de nuestras propias convicciones, certezas "infalibles" o visión de mundo. Ese es uno de los aspectos que más debe enfatizar una educación a través del arte: la alfabetización cultural y política pasa por la capacidad de apropiación crítica del propio devenir existencial, y el diálogo con el arte es una provocación constante a ese angustiante proceso de concientización.

En la tradición brasileña de una epistemología educativa crítica y progresista, los conceptos de Paulo Freire de "contexto teórico" y "alfabetización política”, también de orientación marxista, guardan una estrecha relación con la asociación que hace Jameson entre mapa cognitivo y conciencia de clase. Para Freire el "analfabeto político" es aquel que, aun sabiendo leer y escribir, e incluso poseyendo un alto nivel de instrucción, tiene una percepción ingenua de los seres humanos en sus relaciones con la realidad social, asumiendo esta como un hecho dado, y no como algo que está siendo. Por ende, la "alfabetización política" implica la superación de esa "percepción ingenua" de la realidad por una "percepción crítica", eso es, la concientización del lugar que se ocupa en el mundo. Freire enfatiza que el proceso de "concientización" no se puede entender fuera de la unidad dialéctica acción-reflexión, práctica-teoría. Por su parte, el concepto de "contexto teórico" también exige ser pensado en unidad dialéctica con el "contexto concreto":

[...] no hay praxis auténtica fuera de la unidad dialéctica acción-reflexión, práctica-teoría. Del mismo modo, no hay contexto teórico 'verdadero a no ser en unidad dialéctica con el contexto concreto'. En este contexto, donde se dan todos los hechos, nos encontramos envueltos por lo real, 'empapados' por él, pero no necesariamen- 
te percibiendo la razón de ser de esos mismos hechos en forma crítica. En el 'contexto teórico', 'tomando distancia' de lo concreto, buscamos la razón de ser de los hechos. En otras palabras, procuramos superar la mera opinión que de ellos tenemos y que la toma de conciencia de los mismos nos proporciona, para llegar a un conocimiento cabal, cada vez más científico de ellos. En el 'contexto concreto' somos sujetos y objetos en relación dialéctica con el objeto; en el 'contexto teórico' asumimos el papel de sujetos conocedores de la relación sujeto-objeto que se da en el contexto concreto para, volviendo a este, actuar mejor como sujetos en relación con el objeto. (FREIRE, 2004, p. 30-31).

Pudiéramos decir que en el arte, tanto el proceso de creación como el diálogo interpretativo con la obra, constituyen momentos de unidad dialéctica, de práctica y teoría, de acción y de reflexión. La obra de arte también genera un "contexto teórico" en el sentido freireano: distanciamiento de lo concreto en el que se indaga por la razón de ser de los hechos; ${ }^{6}$ a su vez, en el proceso de comprensión el receptor debe producir su propio contexto teórico para apropiarse del horizonte de sentido de la obra, y a través del distanciamiento que esta propone "extrañarse"7 de sí mismo, de su propia realidad inmediata, así como de los fenómenos y problemáticas que la obra pone en cuestión. Por eso decimos que el arte contribuye a una cultura política y que es una praxis liberadora. Nos hace experimentar de manera intensa y condensada "contextos teóricos", "representaciones mentales", "mapas cognitivos", "textualizaciones simbólicas", lo cual nos permite asumirnos como sujetos capaces de percibir con distancia crítica la relación sujeto-objeto que se da en el plano de la realidad concreta.

Si volvemos ahora a la hipótesis inicial inspirada en la metáfora cartográfica, a saber: los serios problemas que presentamos hoy, tanto

6 Iuri Lotman, siguiendo a Aristóteles, afirma que en el arte los hechos se nos presentan como reflexiones sobre el ser de esos hechos, mientras que en la realidad concreta existe el hecho en sí: "El arte aspira a ser semejante a la vida, pero no es la vida. Y nunca los confundimos. [...] El arte es un modelo de la vida. Y la diferencia entre ellos es grande. Por eso el crimen en el arte es una investigación del crimen, un estudio de qué es el crimen. Pero en la vida sólo está el crimen. En un caso, la imagen de la cosa, y en el otro, la cosa misma" (LOTMAN, 2012, subrayado nuestro).

7 Extrañamiento, o desfamiliarización, fue la categoría usada por los formalistas rusos para definir el efecto estético causado por el arte (SHKLOVSKI, 2003). a nivel individual como colectivo, para generar representaciones mentales de la posición de clase, género, raza, cultura, etc., que ocupamos en la totalidad social (lo que se traduce en una cultura política alienada); podemos afirmar entonces que el rol a jugar por el arte en la educación, en todas las formas de educación y en todos los niveles, continúa siendo un reducto imprescindible para la formación de cultura política: la conquista cognoscitiva de la capacidad de reescritura de la trayectoria existencial, así como de la conciencia del lugar que se ocupa en el mundo. ${ }^{8}$

En Brasil, la profesora e investigadora Dra. Ana Mae Barbosa (2010), desde su clásico $A$ imagem no ensino da arte, de 1991, alertaba sobre la necesidad impostergable de que la enseñanza de arte propiciara una "alfabetización visual" mediante el desarrollo de habilidades de lectura crítica de la imagen. Para ello, las obras de arte debían ser introducidas sin ningún tipo de prejuicio en el contexto escolar. El contacto sistemático de niños y adolescentes con el arte (más de aquellos que en su medio familiar y social no tendrían esa oportunidad) es condición de posibilidad para aprender a dialogar de forma crítica con el universo visual y simbólico de la cultura. Ana Mae Barbosa reclamaba desde la década del ochenta que la educación formal no podía

8 Esta perspectiva que defendemos concuerda plenamente con la manera en que los autores de una obra como $L a$ educación en el arte posmoderno, responden a la pregunta acerca de la finalidad del arte y de la educación artística en dicha condición histórica: “La función del arte a lo largo de la historia cultural de la humanidad ha sido y continúa siendo la 'construcción de la realidad'. El advenimiento de la posmodernidad no ha modificado en lo esencial su función. [...] La interpretación del sentido, los conceptos y las intuiciones es elusiva, quizá más que nunca antes en la historia. Por esa razón, la finalidad de la enseñanza del arte es contribuir a la comprensión del panorama social y cultural en el que viven todos los individuos. [...] Puede ser útil aclarar la finalidad de la enseñanza del arte por contraste con la educación científica. El principal objetivo de la enseñanza de las ciencias a los alumnos es que éstos puedan entender los fenómenos del mundo natural y las representaciones de esos fenómenos por medio de teorías y afirmaciones científicas. El principal objetivo de la enseñanza del arte es que los alumnos lleguen a entender los mundos sociales y culturales en los que viven" (EFLAND; FREEDMAN; STUH, 2003, p. 124-126, subrayado nuestro). 
darse el lujo de seguir excluyendo de la sala de clase al patrimonio artístico local, nacional y universal, como ocurría hasta aquel momento (BARBOSA, 2010). ${ }^{9}$ La noción de "alfabetización visual" como formación en la lectura crítica de la imagen (artística o de otra naturaleza), recuerda el concepto de "alfabetización política" de Paulo Freire; y aunque Ana Mae Barbosa no establece de manera explícita esa articulación conceptual en su libro, podemos inferir por contexto que su noción de "alfabetización visual" tiene como horizonte englobante a la "alfabetización política", la cual solo es posible mediante una "educación liberadora" que rompa el círculo vicioso de la "domesticación".

Hoy Ana Mae Barbosa puede reconocer con orgullo lo mucho que se ha desarrollado la arte-educación en Brasil en los últimos 25 años. Entre los varios factores que en su opinión han contribuido a ello, se encuentra el giro hacia una concepción posmoderna de la enseñanza de arte protagonizado por su "abordagem triangular": "o pós-modernismo articulou concepções baseadas nas pedagogias críticas, culturais e visuais, atribuindo igual importância aos processos de fazer arte, contextualizá-la e saber ler a imagem, a obra de arte ou o campo de sentido da arte" (BARBOSA, 2018, p. 66). Ese giro, de alguna manera, quedó refrendado por las políticas públicas educacionales cuando en el año 1996 se aprueba la "Lei de Diretrizes e Bases n. 9394/96" y los "Parâmetros Curriculares Nacionais" reconocen a la apreciación artística, la experiencia de "fruir formas artística", como uno de los componentes de la enseñanza de Artes Visuales.

Ahora bien, en una entrevista concedida en Chile en el año 2013, se le pregunta a Ana Mae Barbosa por las causas del desfasaje señalado por algunos autores entre lo que produce el arte contemporáneo y lo que se enseña en la

9 Como se sabe, durante toda la primera mitad del siglo $\mathrm{XX}, \mathrm{y}$ aun hasta las décadas del sesenta y setenta, la visión modernista enfatizó la creatividad infantil basada en la autoexpresión (sin contaminación con el arte de los adultos), como el componente fundamental de la enseñanza de arte. Brasil no fue la excepción. escuela; ¿no puede la educación artística incorporar al currículo lo más vanguardista del arte contemporáneo? La experimentada profesora responde que considera que sí se puede, pero que nunca se hace. Incluso refiere una idea de Arthur Efland, quien también ha manifestado que existe "un arte escolar completamente separado del arte del mundo real, de los artistas". Para Ana Mae Barbosa una de las principales razones que dificulta el trabajar con arte contemporáneo es el hecho de que no todas las ciudades cuentan con museos y galerías a los que llevar a los estudiantes; una experiencia directa con la cual poder trabajar después en la escuela (BARBOSA, 2013, p. 8).

Está claro que en la recepción del arte, y más aun de las prácticas artísticas posmodernas, la relación directa que se establece con las obras en museos y galerías es insustituible. Más cuando se trata de instalaciones, environment, performance, arte conceptual, y el trabajo museográfico de la curaduría en general, que suele funcionar como un dispositivo de significación. Empero, consideramos que más importante aún que las facilidades que brindan las instituciones artísticas para el trabajo educativo, lo es la preparación del profesor para trabajar en la lectura/comprensión de las prácticas artísticas posmodernas en el espacio/tiempo del aula de arte. Para ello, como es evidente, resulta fundamental el nivel de formación, la creatividad y la cultura artística del profesor. El trabajo de selección de la obra adecuada para debatir, analizar y comprender junto a los estudiantes equis problemática, exige creatividad, agudeza y conocimiento de las preocupaciones, carencias, expectativas y caracterización psicopedagógica de los estudiantes. Como bien advierte Ana Mae Barbosa (2003, p. 14):

Somente a ação inteligente e empática do professor pode tornar a Arte ingrediente essencial para favorecer o crescimento individual e o comportamento de cidadão como fruidor de cultura e conhecedor da construção de sua própria nação. [...] Sem a experiência do prazer da Arte, por parte de professores e alunos, nenhuma teoria de Arte-Educação será reconstrutora. 
La complejidad de los procedimientos creativos utilizados por los artistas, así como la complejidad de las problemáticas de diversa índole exploradas por el arte actual, es un contenido semiótico e interdisciplinar al que la arte-educación no debiera renunciar. Sobre todo, porque si como advierte Jameson vivimos en un mundo en el que las redes del poder social son tan minuciosas, en el que las formas de reproducción de ideología son tan sutiles y sofisticadas; y si pensamos, por solo poner algunos ejemplo, en la cantidad variopinta de audiovisuales, video-games y otras formas de entretenimiento provistas por la industria cultural, así como la exposición constante a la publicidad comercial en todas sus formas, etc.: ¿cuál sería la visión de mundo que esos referentes culturales aportan al Orden de lo Simbólico de niños y adolescentes?, ¿cuántos estereotipos, prejuicios de clase, genero, sexo, raza, estética en general, etc., reproducen y convierten en patrones a seguir? ¿Se puede trabajar en la deconstrucción de esos estereotipos que modelan una visión simplificada y alienada de la complejidad de la sociedad contemporánea, a través del arte tradicional o moderno? ¿Cómo generar mapas cognitivos a escala de ciudad, país, región geográfica, sociedad global, así como de las innumerables problemáticas relacionables a esas escalas?

Evidentemente, si la arte-educación no se abre a la producción artística contemporánea, dichas problemáticas, y muchas otras, indecibles, innumerables, nunca entrarán a formar parte de los contenidos de la enseñanza de artes visuales en la educación formal.

Pensemos en los fenómenos que generan las tecnologías informáticas de comunicación: nueva experiencia del espacio y del tiempo; conectividad global; acceso a los mismos servicios e información desde cualquier parte del planeta; simultaneidad de procesos; superposición de ese presente virtual de flujos de comunicación sobre la realidad concreta; dificultad, casi imposibilidad, de representación mental de esa cartografía virtual y global; etc. No fue por acaso que Jameson propuso en el ensayo estudiado que el nuevo "objeto de lo sublime" en la sociedad posmoderna eran esos complejos fenómenos desencadenados por las “tecnologías de reproducción”, como él les llamo.

El arte, que siempre ha gustado de estudiar fenómenos que escapan a todo esfuerzo de representación, no ha estado ajeno a dichas problemáticas, por lo que no es difícil identificar hoy un gran número de obras de la más diversa naturaleza, con las cuales poder trabajar esos temas en el espacio del aula. Pongamos como ejemplo Electronic Superhighway (1995), del artista coreano/norteamericano Nam June Paik (1932-2006). Con un puñado de imágenes de buena calidad, cualquier profesor competente puede desarrollar metodológicamente un ejercicio interpretativo de una instalación de grandes dimensiones, confeccionada con materiales diversos, si se parte de una descripción eficiente de la manera en que se estructura la obra y de los componentes que la conforman.

Electronic Superhighway representa el mapa de los EE. UU., incluidos los estados de Alaska y Hawaii; pero se trata de un mapa dibujado objetualmente con luces de neón. La superficie de ese gigantesco mapa está cubierta por pantallas de televisores, los cuales emiten contenidos provenientes de 51 canales de video. Las luces de neón de variados colores, así como los destellos de luz que emiten las pantallas, conforman una superficie brillosa, espectacular, alucinante, de un espacio físico que comienza a transformarse en un espacio virtual, de flujos simultáneos de información.

El título de la obra, que en su traducción significa "autopista electrónica”, sería uno de los primeros elementos a destacar por el profesor para comenzar a generar un proceso interpretativo. Nam June Paik fue pionero en proponer el término electronic superhighway, que hoy se usa como metáfora de la Red de redes. Por la manera en que construye la cartografía del espacio geográfico de los EE. UU., el artista se sitúa en el límite ambivalente entre dos mapas 
cognitivos de una sociedad en transformación. Por una parte, la modernidad de un gran país, conectado en el nivel terrestre por un sistema de autopistas interestatales, y en el nivel virtual por millones de pantallas de televisión implosionando en los hogares, uniendo a la nación en una cultura (ideología) común, de hábitos, estilos de vida, valores, comportamientos, etc. Pero en un segundo nivel de interpretación, esas luces de neón que recuerdan la llamada de los moteles y restaurantes de carretera, el desplazamiento en automóvil, etc., se transmutan en "autopistas electrónicas". Es así que otro tipo de conectividad emerge y configura un nuevo espacio virtual que uniría al mundo en una gran red de tráfico de datos: esa es la condición de la sociedad posmoderna global.

Por tanto, esta obra de Nam June Paik es un mapa estético y cognitivo que condensa la mutación hacia el futuro que se estaba gestando en la década del noventa: a las redes de autopistas terrestres se sumaron redes electrónicas, y a las pantallas de televisión se sumaron las de computadoras, tablets, teléfonos inteligentes, a través de cuyas interfaces, y sentados en la intimidad del hogar, podemos hacer infinitos viajes mucho más allá de las fronteras de las culturas nacionales. Por eso su obra, como diría Fredric Jameson, nos permite comprender algo de la estructura del mundo actual.

Figura 1 - Electronic Superhighway.

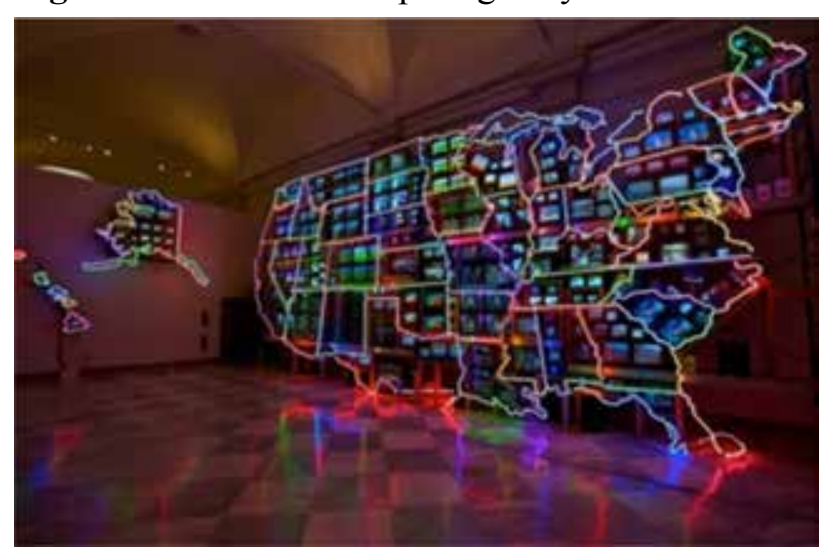

Fuente: Hakala (2018).

El profesor debe lograr involucrar a todos los estudiantes en el diálogo con la estruc- tura artística, explotando todas sus sutilizas formales, semánticas, metafóricas, etc. Debe saber propiciar, con las preguntas adecuadas y brindando solo información imprescindible, un clima de excitación sensorial que poco a poco se vaya transformando en un trabajo intelectual de interpretación, sin imponer nunca su criterio de autoridad. Más bien el maestro debiera propiciar un proceso horizontal de comprensión, construido en colectivo, pero a través de la emoción y las ideas aportadas por cada cual.

La obra comentada puede servir para poner en debate cuestiones tan importantes como la manera en que los diferentes tipos de conexión, sean físicas o virtuales, desde las más primitivas del pasado hasta las formas tecnológicas más sofisticadas del presente, son de vital importancia para la vida humana estructurada en sociedad; y cómo cada cambio en esas formas de conexión, propiciado por avances tecnológicos, ha traído como consecuencia cambios trascendentales en la manera en que funcionamos en sociedad. Pero más importante aún que ese contenido, y que otros muchos que la obra permitiría abordar, es la reflexión individual de cada estudiante, la manera en que el diálogo con la obra les puede ayudar a comprender, desde la experiencia individual, el fenómeno de la comunicación, del acceso y uso de la información, de la conexión con el otro, a escala personal, nacional, global, etc.

Ese situarse en la problematización de contenidos desde la reflexión individual, es lo que conduce a la reescritura, la textualización o concientización de la experiencia propia, del saber que se posee. Y ese saber, esa estructuración cognoscitiva que emerge en la experiencia estética individual, tampoco puede ser medido o evaluado con las categorías de lo cierto o lo errado; porque el arte es un laboratorio tanto de formas comunicativas como de ideas, por lo que sus síntesis dialécticas escapan constantemente de las "certezas" instituidas. Al respecto, recurrimos por última vez a las sabias palabras de Ana Mae Barbosa (2013, p. 4): 
¿Cuál es el gran problema de la escuela? Es lo cierto y lo errado. Primero le enseño algo, después le hago una prueba para ver si usted aprendió aquello de lo que se le enseñó? En Artes Visuales no hay cierto ni errado. Hay más adecuado, menos adecuado. Más creativo, menos creativo. Pero no un cierto o errado. Un buen profesor sabe lidiar con esta posibilidad de que esté no tan adecuado, pero con preguntas va llevando a justificar, por ejemplo, en un cuadro aquello que el niño ha visto.

$\mathrm{Si}$ alguna riqueza tiene el arte, como bien hubo de señalar metafóricamente Gadamer, es que la obra necesita, para poder hablar, de la voz de su intérprete. Por consiguiente, una obra tendrá tantas voces como intérpretes posibles. $Y$ en la medida en que logramos hacer hablar al arte, fortalecemos nuestra voz, nuestro lenguaje, nuestra capacidad de construir sentido. Ampliamos, también, nuestro Orden de lo Simbólico, esa realidad propiamente humana en la que existimos.

\section{REFERENCIAS}

ALTHUSSER. Louis. Dos cartas sobre el conocimiento del arte. Pensamiento Crítico, La Habana, n. 10, p. 111-121, noviembre de 1967.

Ideología y aparatos ideológicos de Estado. Freud y Lacan. Buenos Aires: Nueva Visión, 2003.

BARBOSA, Ana Mae. A imagem no ensino da arte: anos 1980 e novos tempos. São Paulo: Perspectiva, 2010.

As mutações do conceito e da prática. In: (Org.). Inquietações e mudanças no ensino da arte. São Paulo, Cortez, 2003. p. 13-25.

Em defesa da arte-educação. Observatório Itaú Cultural, n. 24, p. 66-75, jun./dez. 2018. Disponible en: <http://www.itaucultural.org.br/ revista-observatorio-24-arte-cultura-e-educacao-na-america-latina> Acceso en: 15 ago. 2018.

. Entrevista. Observatorio Cultural, Consejo Nacional de la Cultura y las Artes, Gobierno de Chile, 2013. Disponible en: <http://www.observatoriocultural.gob.cl/wp-content/uploads/2015/02/ Entrevista-Ana-Mar\%C3\%ADa-Barbosa_Observatorio-Cultural.pdf>. Acceso en: 28 oct. 2018.

BELL, Daniel. Las contradicciones culturales del capitalismo. México D. F.: Alianza Editorial, 1989.

EFLAND, Arthur; FREEDMAN, Kerry; STUH, Patricia. La educación en el arte posmoderno. Barcelona: Ediciones Paidós Ibérica, 2003.

FREIRE, Paulo. La importancia de leer y el proceso de liberación. México D. F.: Siglo XXI Editores, 2004.

HAKALA, Rozanne. Rozanne Hakala Photography. Disponible en: <https://rozannehakala.photoshel-

ter.com/image/I0000vEt611iyoac>. Acceso en: 29 ago. 2018.

JAMESON, Fredric. El giro cultural: escritos seleccionados sobre el posmodernismo 1983-1988. Buenos Aires: Manantial, 2002.

. El posmodernismo o la lógica cultural del capitalismo tardío. Casa de las Américas, La Habana, v. 26, n. 155/156, p. 141-173, 1986.

Ensayos sobre el posmodernismo. Buenos Aires: Ediciones Imago Mundi, 1991.

Imaginario y simbólico en Lacan. Buenos Aires: Ediciones El Cielo por Asalto, 1995.

Marxism and form: twentieth century dialectical theories of literature. Princeton: Princeton University Press, 1971.

Postmodernism, or, the cultural logic of late capitalism. New Left Review, I, n. 146, jul./ago. 1984. Disponible en: <https://newleftreview.org/I/146/ fredric-jameson-postmodernism-or-the-cultural-logic-of-late-capitalism>. Acceso em: 22 ago. 2018.

. Posmodernismo y capitalismo tardío. Entrevista con Horacio Machín. El Cielo por Asalto, año 1, n. 3, p. 45-58, 1992.

Raymond Chandler: the detections of totality. London: Verso, 2016.

LACAN, Jacques. El estadio del espejo como formador de la función de yo [je] tal como se nos revela en la experiencia psicoanalítica. En: Escritos I. México D. F.: Siglo XXI Editores, 2003a.

. Función y campo de la palabra y del lenguaje en psicoanálisis. En: ___ Escritos I. México D. F.: Siglo XXI Editores, 2003b. 
De los nombres del padre. Buenos Aires: Paidós, 2005.

LACAN, Jacques; GRANOFF, Wladimir. Fetichismo: lo simbólico, lo imaginario y lo real. Acheronta. Disponible en: <http://www.acheronta.org/lacan/ fetichismo.htm>. Acceso en: 22 ago. 2018.

LOTMAN, Iuri. Sobre la naturaleza del arte. Denken Pensée Thought Mysl... Boletín digital del Centro Teórico-Cultural Criterios, La Habana, n. 22, marzo 2012.

LYNCH, Kevin. The image of the city. Cambridge: Massachusetts Institute of Technology, 1990.
RICART, Núria. El mapa cognitivo. Desarrollos en el arte del siglo XX. Universidad de Barcelona, 2009. Disponible en: <http://hdl.handle. net/2445/22902>. Acceso en: 13 ago. 2018.

SHKLOVSKI, Víctor. El arte como artificio. En: ARAÚJO, Nara; DELGADO, Teresa (Coord.). Textos de teorías y crítica literarias (Del formalismo a los estudios postcoloniales). La Habana: Universidad de La Habana/Universidad Autónoma Metropolitana de México, 2003. p. 19-30.

Recebido em: 02/02/2019 Aprovado em: 02/04/2019 